\title{
Community willingness to perform cardiopulmonary resuscitation: the Crimean survey
}

\section{Alexei Birkun, ${ }^{1}$ Yekaterina Kosova ${ }^{2}$}

${ }^{1}$ Medical Academy named after S. I. Georgievsky of V. I. Vernadsky Crimean Federal University, Simferopol, Russia (e-mail: birkunalexei@gmail.com)

\section{Taurida Academy of V. I. Vernadsky Crimean Federal University, Simferopol, Russia}

Background and Purpose of the Study: So far, almost nothing is 80 known about the readiness of lay people to perform cardiopulmonary resuscitation (CPR) in the former USSR countries. This study was aimed to evaluate willingness to attempt CPR and 60 elucidate barriers to perform CPR in the selected population of the post-Soviet area.

Materials and methods: A personal interview survey of adult lay public of the Crimean peninsula was conducted in November 2017- 30 January 2018. The sample size needed to reflect the target population was calculated as 384 using the Cochran formula ( $\pm 5 \%$ margin of error; $95 \%$ confidence level). Willingness to attempt CPR in real life was 10 evaluated using a 5-point numeric rating scale (from 1 - definitely will not do CPR to 5 - definitely will do (PR), and potential barriers to perform CPR on a stranger or a friend/relative were inquired with multiple-choice questions. Respondents' characteristics were compared with regard to willingness to perform CPR by chi-square test or Fisher's exact test, and variables with confirmed association $(p<0.05)$ were included in a binomial logistic regression analysis.

Table. Distribution of responses to the multiple-choice questions querying potential barriers to attempt CPR in real life.

\begin{tabular}{|c|c|c|}
\hline Potential barriers to perform CPR & $\begin{array}{c}\text { CPR on a } \\
\text { stranger, } n \\
(\%)\end{array}$ & $\begin{array}{l}\text { CPR on a } \\
\text { relative/ } \\
\text { friend, } n \text { (\%) }\end{array}$ \\
\hline Lack of CPR knowledge and skills & $257(27.0)$ & 169 (44.1) \\
\hline Fear to cause harm to a victim & $240(25.2)$ & $137(35.8)$ \\
\hline $\begin{array}{l}\text { Unpleasant external appearance of a } \\
\text { victim }\end{array}$ & $122(12.8)$ & $5(1.3)$ \\
\hline Fear of legal implication & $98(10.3)$ & $18(4.7)$ \\
\hline $\begin{array}{l}\text { Fear of catch an infection on a contact } \\
\text { with a victim }\end{array}$ & $92(9.7)$ & $8(2.1)$ \\
\hline Personal physical limitations & $71(7.5)$ & $28(7.3)$ \\
\hline Reluctance to be in the focus of attention & $33(3.5)$ & $6(1.6)$ \\
\hline $\begin{array}{l}\text { Personal problems requiring urgent } \\
\text { solution }\end{array}$ & $23(2.4)$ & $3(0.8)$ \\
\hline Opposite sex of a victim & $8(0.8)$ & $2(0.5)$ \\
\hline Other & $8(0.8)$ & $7(1.8)$ \\
\hline Total & $952(100.0)$ & $383(100.0)$ \\
\hline
\end{tabular}

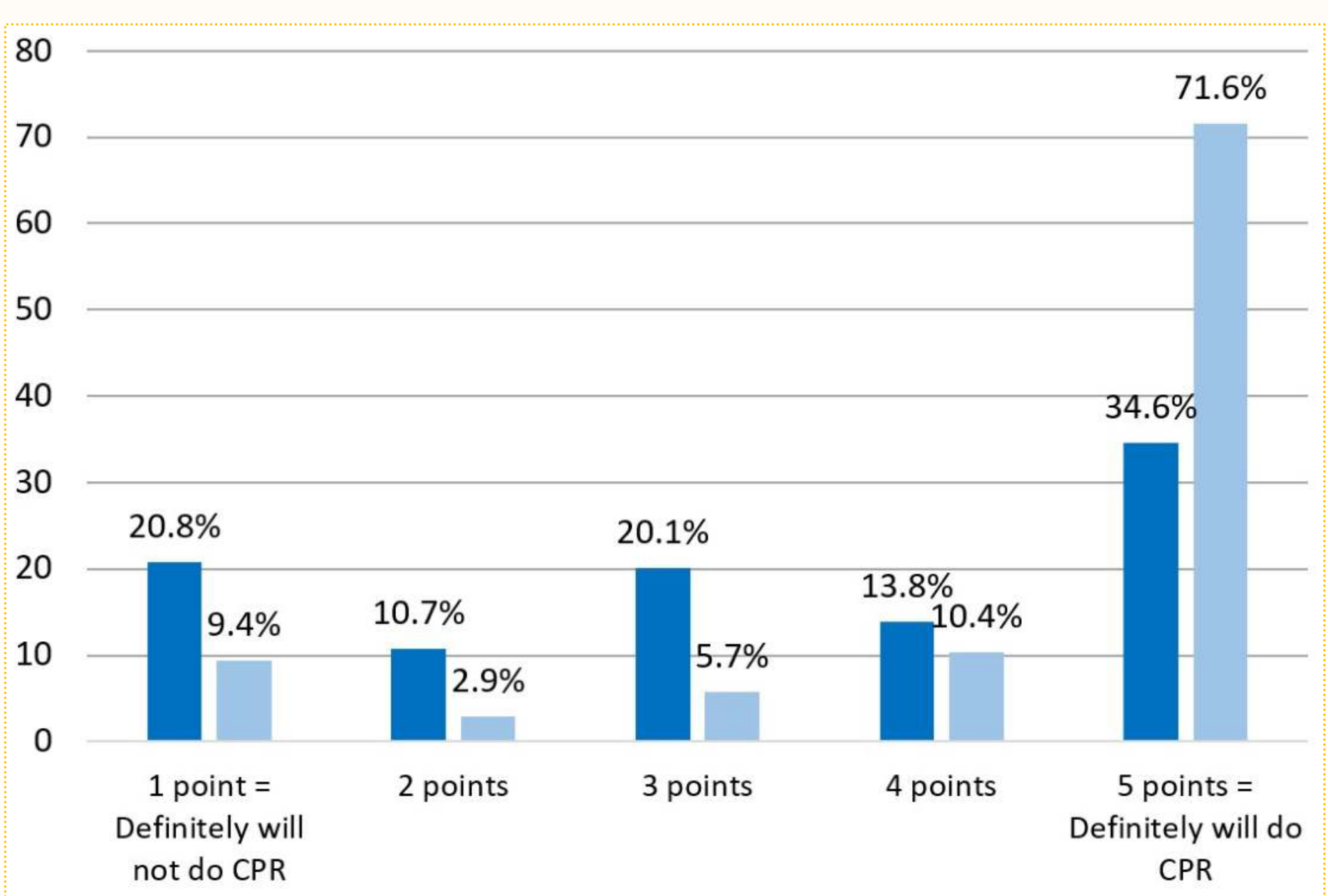

Willingness to perform CPR on a stranger $\quad$ Willingness to perform CPR on a relative/friend Figure. Percentage distribution of respondents according to their willingness to do CPR in real life.

Results: The majority of respondents expressed at least some willingness to perform CPR on a stranger (304 of 384, 79\%) or a friend/ relative (348 of 384, 91\%) (Figure). About 35\% and $72 \%$ participants stated they will definitely do CPR on a stranger or a loved one, respectively.

Willingness to perform CPR was positively associated with previous CPR training $(p \leq 0.012)$ and self-perceived level of CPR knowledge $(p<0.001)$, but independent from the number of attended courses, timing of last training, experience of cardiac arrest in real life, selfperceived health state, sex, place of residence (urban/rural), marita status, educational level, occupation, medical education or monthly income $(p>0.05)$.

Whereas younger respondents were more willing to attempt CPR on a stranger ( $p=0.038$ ), the willingness to provide CPR on a loved one was independent from age ( $p>0.05)$.
In binomial logistic regression, willingness to attempt CPR on a stranger was found to be predicted by willingness to learn CPR (OR: 2.0; 95\% Cl: 1.1-3.4), at least poor selfperceived knowledge of CPR (OR: 6.9; 95\% Cl: 3.8-12.7) and serious health problems in friends/relatives (OR: 2.8; 95\% Cl: 1.4-5.3). The willingness to perform CPR on a loved one significantly correlated with at least poor selfperceived knowledge of CPR (OR: $5.4 ; 95 \% \mathrm{Cl}$ : 2.6-11.3) and the true knowledge of hand position for chest compressions (OR: 3.5; 95\% Cl: 1.4-8.8).

The potential barriers to attempt CPR were much more commonly reported when hypothesizing cardiac arrest in a stranger than in a loved one (952 vs. 383, respectively) (Table). The fear to cause harm to a victim and lack of CPR knowledge and skills were the commonest barriers to perform CPR. Further, when several barriers were reported, fear to cause harm or lack of CPR knowledge/ skills were most frequently perceived as the strongest barrier to attempt resuscitation (32\% and 34\%, respectively, for CPR on a stranger, $20 \%$ and $29 \%$ for CPR on a friend/relative). Overall, $10 \%$ and $46 \%$ respondents reported no barriers when supposing CPR attempt on a stranger or on a loved one, respectively.

Conclusions: The results show high rates of readiness to attempt CPR in the Crimean population with higher willingness to perform CPR on a loved one, than on a stranger. Considering previously trained are declaring higher willingness to attempt CPR, and the lack of resuscitation knowledge and fear to cause harm constitute the main barriers to perform CPR, there is a potential to increase the willingness by means of enhancing public education in resuscitation. 